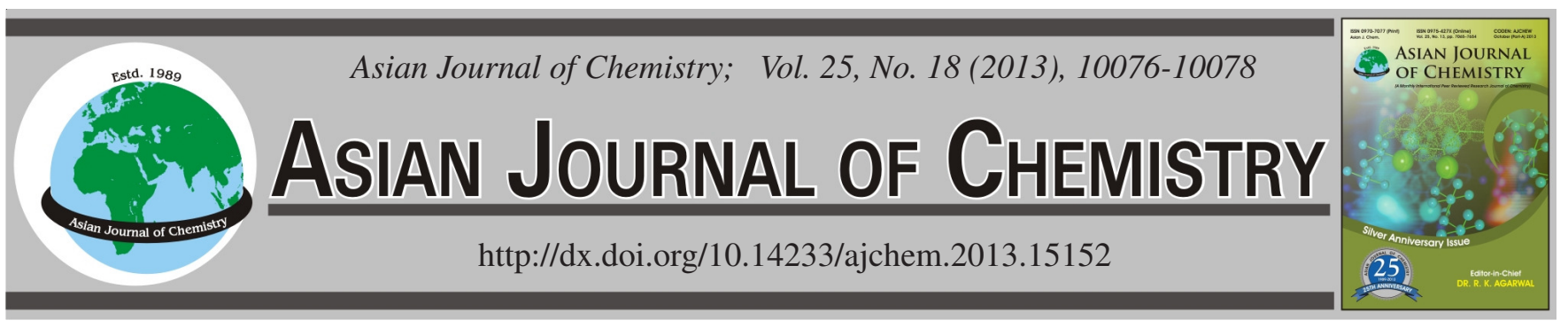

\title{
Root Exudates in Hippophae rhamnoides of Different Growth States Detected by GC-MS
}

\author{
Zhe Dong, TianXing Wei" and Qingke Zhu
}

School of Soil and Water Conservation, Beijing Forestry University, Beijing 100083, P.R. China

*Corresponding author: Fax: +86 10 62338689; Tel: +86 10 62336071; E-mail: weitx@bjfu.edu.cn

(Received: 15 January 2013;

Accepted: 5 November 2013)

AJC-14338

The root exudates of Hippophae rhamnoides naturally growing in hilly region of Loess Plateau were detected by gas chromatography-
mass spectrum. Root exudates released from Hippophae rhamnoides of different growth states are similar and mainly of acids. The
percentage of organic acids, phenolic acids and fatty acids in better-grown Hippophae rhamnoides are, respectively 21.248 .15 and 17 ,
while in poor-grown Hippophae rhamnoides are 7.2, 30.52 and 33.79 and in the dead one are $58.74,23.59$ and 5.16 . Teradecanoic acid
and hexadecanedioic acid have adverse effect on the growth of Hippophae rhamnoides. Acetic acid and butenedioic acid are related to
Hippophae rhamnoides's death. Diphenylamine in rhizosphere soil is an external factor affecting Hippophae rhamnoides's growth.

Key Words: Hippophae rhamnoides, Root exudates, GC-MS.

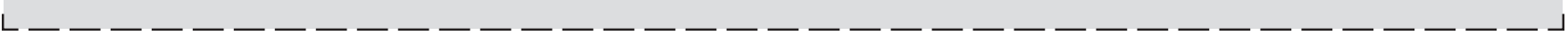

\section{INTRODUCTION}

Hippophae rhamnoides is one of pioneer species that have been widely planted in gully region of Loess Plateau in China ${ }^{1}$. Ecological benefits of Hippophae rhamnoides have decreased mainly because lack of water and low tending management. The research of Zhou et al. ${ }^{2}$ proved resistance of Hippophae rhamnoides to $H$. hippophaecolus induced by soil moisture. External environment affects Hippophae rhamnoides's growth and the growth states also affect external environment. Li et al. ${ }^{3}$ proved that different ages of Hippophae rhamnoides have a certain relationship with microbial diversity. Yu et al. ${ }^{4,5}$ studied cucumber and cotton have allelopathic potential by releasing allelochemicals into the rhizosphere. It is reasonable to speculate that root exudates of Hippophae rhamnoides might be the internal factors affecting their growth. But nothing is known yet about the effect of root exudates released from Hippophae rhamnoides on its growth. So it is important to investigate the compounds of root exudates and speculate their effects on Hippophae rhamnoides's growth by comparing Hippophae rhamnoides of different growth states.

\section{EXPERIMENTAL}

The roots and rhizosphere soil of Hippophae rhamnoides were collected in Gully region of Loess Plateau in July 2011.

General procedure: the roots and the rhizosphere soil were washed with $50 \mathrm{~mL} 1 \mathrm{~mol} / \mathrm{L} \mathrm{NaOH}$ after air-dried. The residual liquid was collected and filtered 2-3 times. Take 20 $\mathrm{mL}$ filtrate as subject. The filtrate was adjusted $\mathrm{pH}$ to 2.5-3.0 and dripped with saturated $\mathrm{NaCl}$ and then extracted with ether three times. The extraction was dried at $40^{\circ} \mathrm{C}$ on a rotary evaporator and was dissolved by $1 \mathrm{~mL}$ methanol, then moved to diameter of 1.8-2.0 mm capillaries. The capillaries were placed in a vacuum desiccator and pumped to dry and then added in $8 \mu \mathrm{L}$ BSTFA to derive $1 \mathrm{~h}$ at $100^{\circ} \mathrm{C}$ for further GC-MS analysis.

Detection method: Root exudates of Hippophae rhamnoides were detected by gas chromatography-mass spectrum (GC-MS). Chromatographic column was silica capillary column $(30 \mathrm{~m} \times 0.32 \mathrm{~mm} \times 0.25 \mu \mathrm{m})$ made in Perkin Elmer. GC and MS conditions were as described: Column temperature starts from $50^{\circ} \mathrm{C}$ (kept for $3 \mathrm{~min}$ ) with a $8^{\circ} \mathrm{C} / \mathrm{min}$ rate up to $180^{\circ} \mathrm{C}$ (kept for $1 \mathrm{~min}$ ), then with $10^{\circ} \mathrm{C} / \mathrm{min}$ rate up to $280{ }^{\circ} \mathrm{C}$ (kept for $5 \mathrm{~min}$ ) with helium as the carrier gas at constant pressure. The interface temperature is set at $260{ }^{\circ} \mathrm{C}$ controlled by constant electronic flow. Split less injection with injection volume of $0.6 \mu \mathrm{L}$. EI-mass spectra was taken at $70 \mathrm{eV}$, interface temperature was $250^{\circ} \mathrm{C}$, mass ranges from 29-500, voltage of the detector was set at $400 \mathrm{~V}$ and full-scan is finished within $0.2 \mathrm{~s}$.

\section{RESULTS AND DISCUSSION}

The root exudates released from better-grown Hippophae rhamnoides (BG), poor-grown Hippophae rhamnoides (PG) and the dead one (D) are mainly of acids accounting for 86.35 , 72.22 and $87.95 \%$, respectively and contain 33, 28 and 21 active substances, respectively (Table-1). This shows Hippophae rhamnoides of different growth states have different types of root exudates. 
TABLE-1

MAJOR COMPONENTS OF ROOT EXUDATES RELEASED FROM Hippophae rhamnoides IN DIFFERENT GROWTH STATES

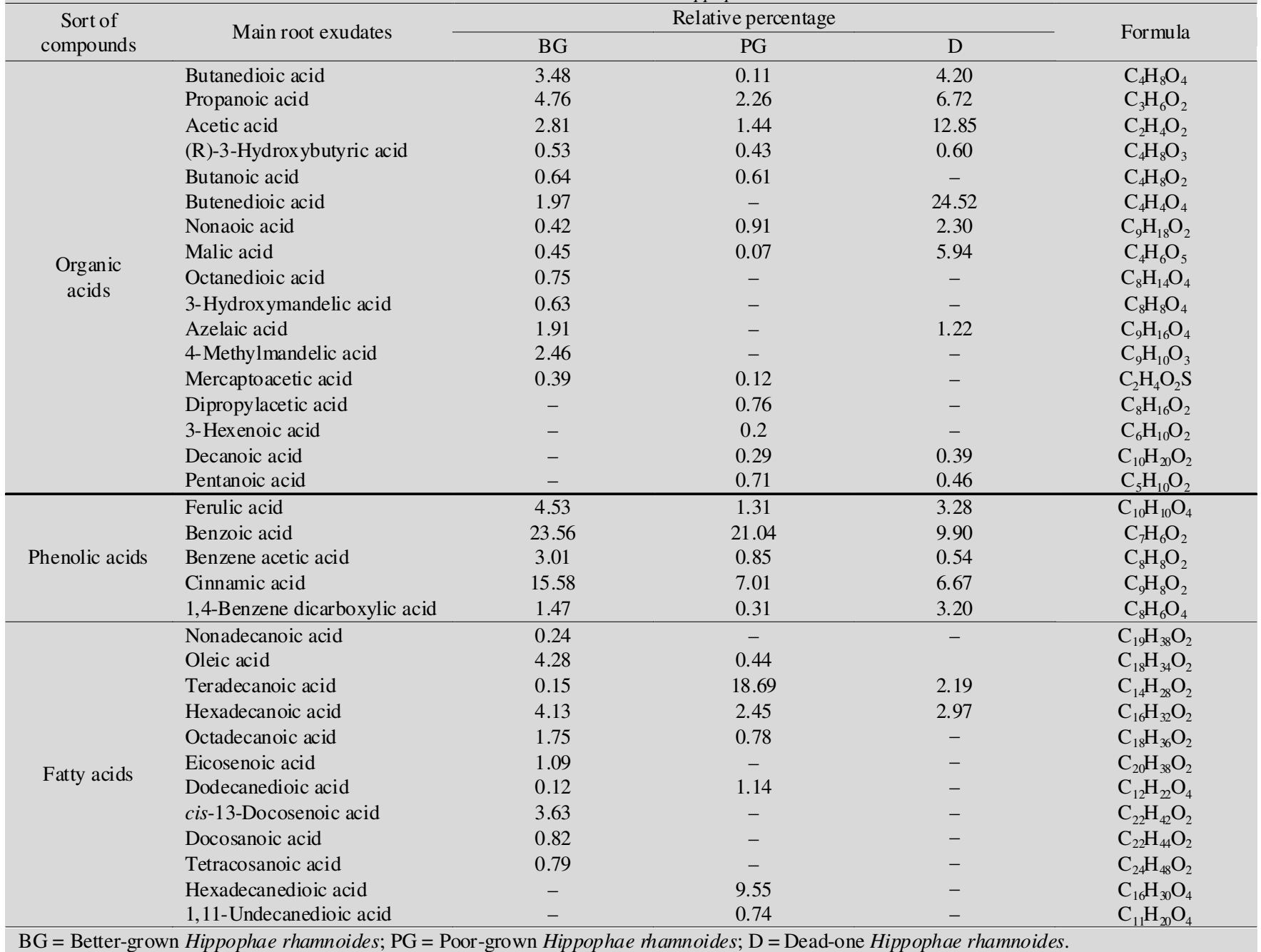

Acids in root exudates can be divided into organic acids, phenolic acids and fatty acids. The relative proportion of organic acids, phenolic acids and fatty acids in better-grown Hippophae rhamnoides are $21.2,48.15$ and $17 \%$, respectively and in poor-grown Hippophae rhamnoides are 7.2, 30.52 and $33.79 \%$ and in the dead one are 58.74, 23.59 and $5.16 \%$. Obviously, the organic acids degree are D > BG > PG; the phenolic acids degree are $\mathrm{BG}>\mathrm{PG}>\mathrm{D}$ and the fatty acids degree are $\mathrm{PG}>\mathrm{BG}>\mathrm{D}$. Acetic acid and butenedioic acid in the dead Hippophae rhamnoides are significantly higher in proportion than the better-grown and poor-grown Hippophae rhamnoides which might contribute to the death of Hippophae rhamnoides. Phenolic acids have allelopathic potential. Many studies showed that benzoic acid and cinnamic acid could affect the activity of protective enzymes in the root cells, membrane permeability $^{6,7}$ and increase the risk of infection ${ }^{8}$. However, these adverse effects are related to the concentration of phenolic acids. Higher contents of phenolic acids in better-grown Hippophae rhamnoides shows no threat to growth, while poorgrown Hippophae rhamnoides and the dead one have lower levels of phenolic acids. This shows it is not better with lower level of acids. Benzoic acid and cinnamic acid are two most important compounds of phenolic acids at relatively higher percentage compared with other acids.

\begin{tabular}{cc} 
& TABLE-2 \\
& RELATIVE PERCENTAGE OF \\
\multicolumn{2}{c}{ DIPHENYLAMINE IN RHIZOSPHERE SOIL } \\
\hline Growth states & Relative percentage of diphenylamine (\%) \\
\hline BG & 7.15 \\
PG & 11.05 \\
D & 15.66 \\
\hline
\end{tabular}

Most studies of autotoxic components in root exudates paid more attention to phenolic acids than to fatty acids. This study shows that fatty acids also take adverse effects on plant growth. Teradecanoic acid has higher level than other acids in root exudates of poor-grown Hippophae rhamnoides and hexadecanedioic acid only detected in poor-grown Hippophae rhamnoides could conclude these two fatty acids are related to the poor growth.

Diphenylamine, an organic pollutant ${ }^{9}$, detected in rhizosphere soil (Table-2) has adverse effects on the growth of Hippophae rhamnoides. The comparison of relative proportion of diphenylamin in better-grown, poor-grown and dead Hippophae rhamnoides is $\mathrm{D}>\mathrm{PG}>\mathrm{BG}$. So diphenylamine is one of the external factors that cause poor growth of Hippophae rhamnoides. The result also shows that the worse growth, the higher content of diphenylamine in the rhizosphere soil. We should take deeper research to decide whether the content of 
phenolic acids in root exudates have any relation with degradation of diphenylamine.

\section{Conclusion}

The external environment affects the growth states of plants which induced difference of root exudates and affects external environment in adverse. This study showed diphenylamine in rhizosphere soil had adverse affects on growth of Hippophae rhamnoides which made difference of root exudates in their kinds and amounts. Phenolic acids are allelochemicals but its relatively high percentage has no adverse effect on Hippophae rhamnoides's growth whereas its proportion in poor-grown Hippophae rhamnoides and the dead ones are lower. Most studies of autotoxic components in root exudates paid little attention to fatty acids. The results showed that teradecanoic acid and hexadecanedioic acid could have some affections on Hippophae rhamnoides's growth and should get more attention.

\section{ACKNOWLEDGEMENTS}

This work is supported by the Fundamental Research Funds for the Central Universities (BLJD200909) and (National Key Technology R \&D Program) 2011BAD38B06.

\section{REFERENCES}

1. G.L. Wang, G.B. Liu, F. Li, X.L. Hou and S.L. Zhou, Acta Ecol. Sin., 23, 2550 (2003).

2. Z.Y. Zhou, W.L. Yin and H.J. Liang, J. Beijing Forestry Univ., 29 (2007).

3. Y.X. Li, Z. Zhao, J.Q. Chen and E.T. Liu, J. Northwest A F Univ. (Nat. Sci. Ed.), 38 (2010).

4. J.Q. Yu and Y. Matsui, J. Chem. Ecol., 20, 21 (1994).

5. J.G. Liu, Y.B. Li, G.Y. Jiang, X.M. Bian, F. Li and W. Geng, Allelopathy J., 21, 299 (2008).

6. E.P. Zhang, W.B Zhang, S.H. Zhang, I. Liang and T.L. Ii, Acta Agric. Boreali-Occidentalis Sin., 19 (2010).

7. B. Politycka, Acta Physiol. Plantarum, 19, 311 (1997).

8. S.F. Ye, J.Q. Yu, Y.H. Peng, J.H. Zheng and L.Y. Zou, Plant Soil, 263, 143 (2004).

9. Y. Yang, F.Z. Wu and S.W. Liu, Allelopathy J., 27, 75 (2011). 